\title{
Visible Light Anthraquinone Functional Phthalocyanine Photoinitiator for Free Radical and Cationic Polymerizations
}

Louise Breloy, Vlasta Brezova, Agata Blachenik-Grosnik, Marc Presset, Mustafa Semih Yildirim, Ismail Yilmaz*, Yusuf Yagci, Davy-Louis Versace*

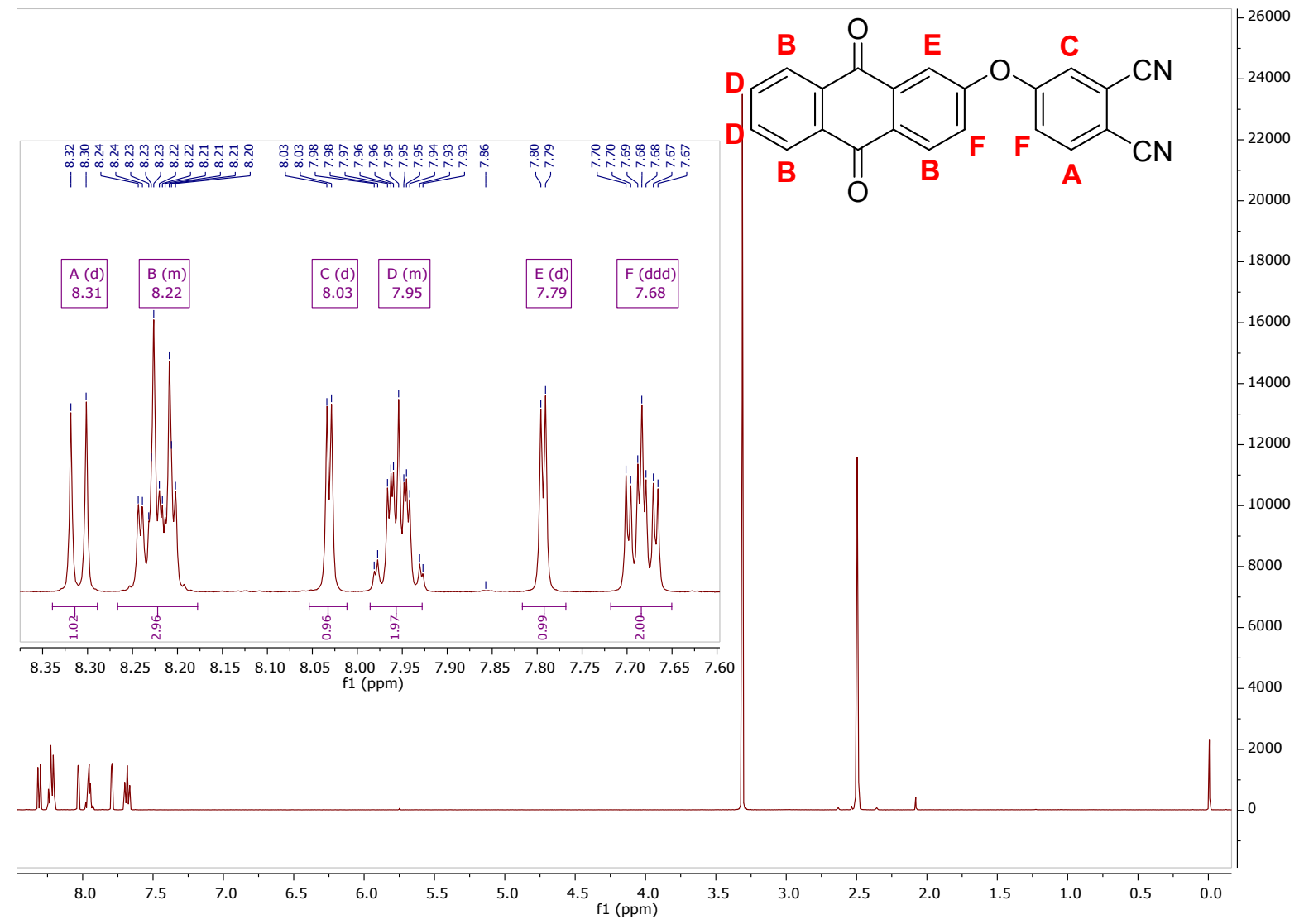

Figure S1. ${ }^{1} \mathrm{H}$ NMR spectrum of 3 


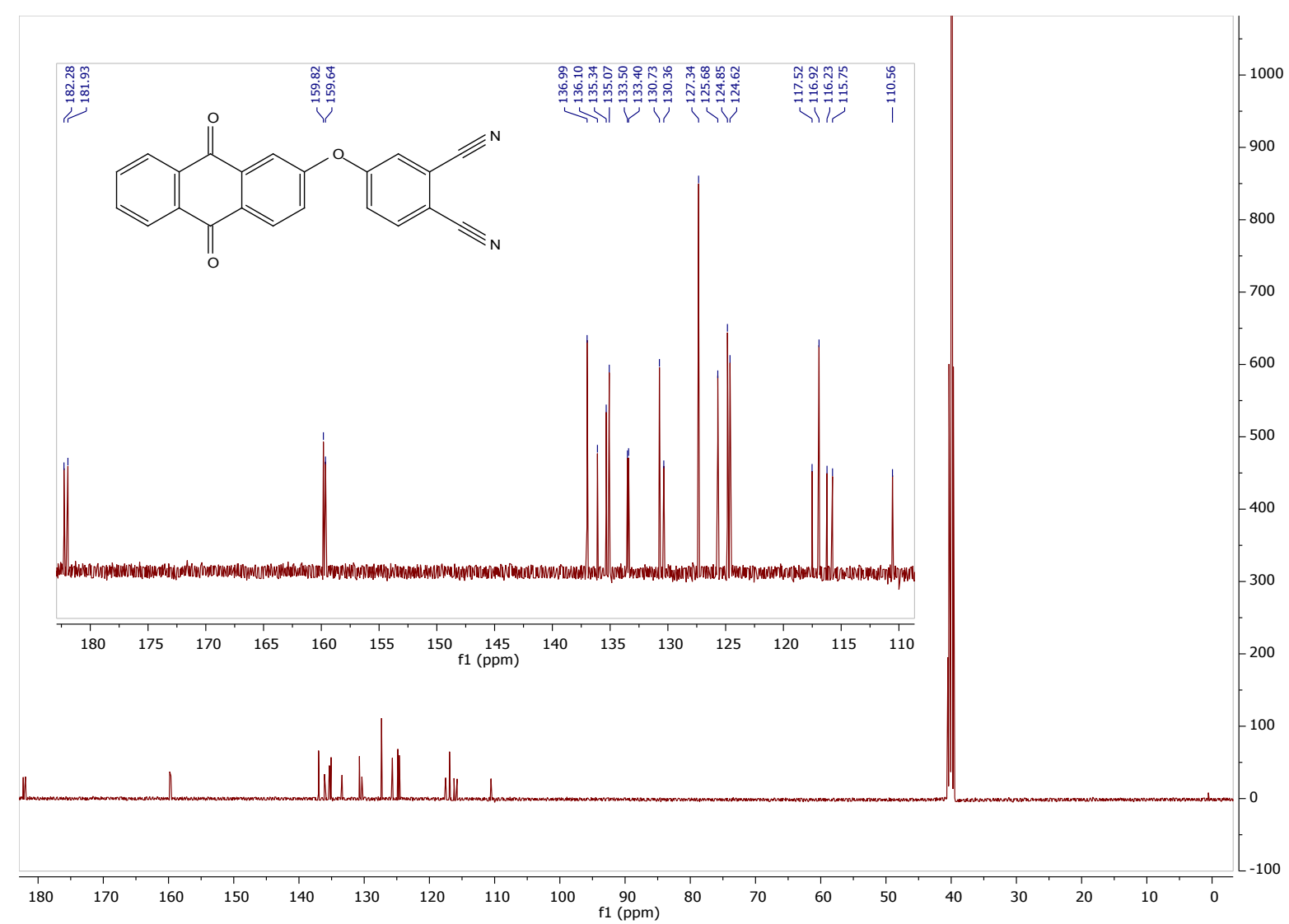

Figure S2. ${ }^{13} \mathrm{C}$ NMR spectrum of $\mathbf{3}$

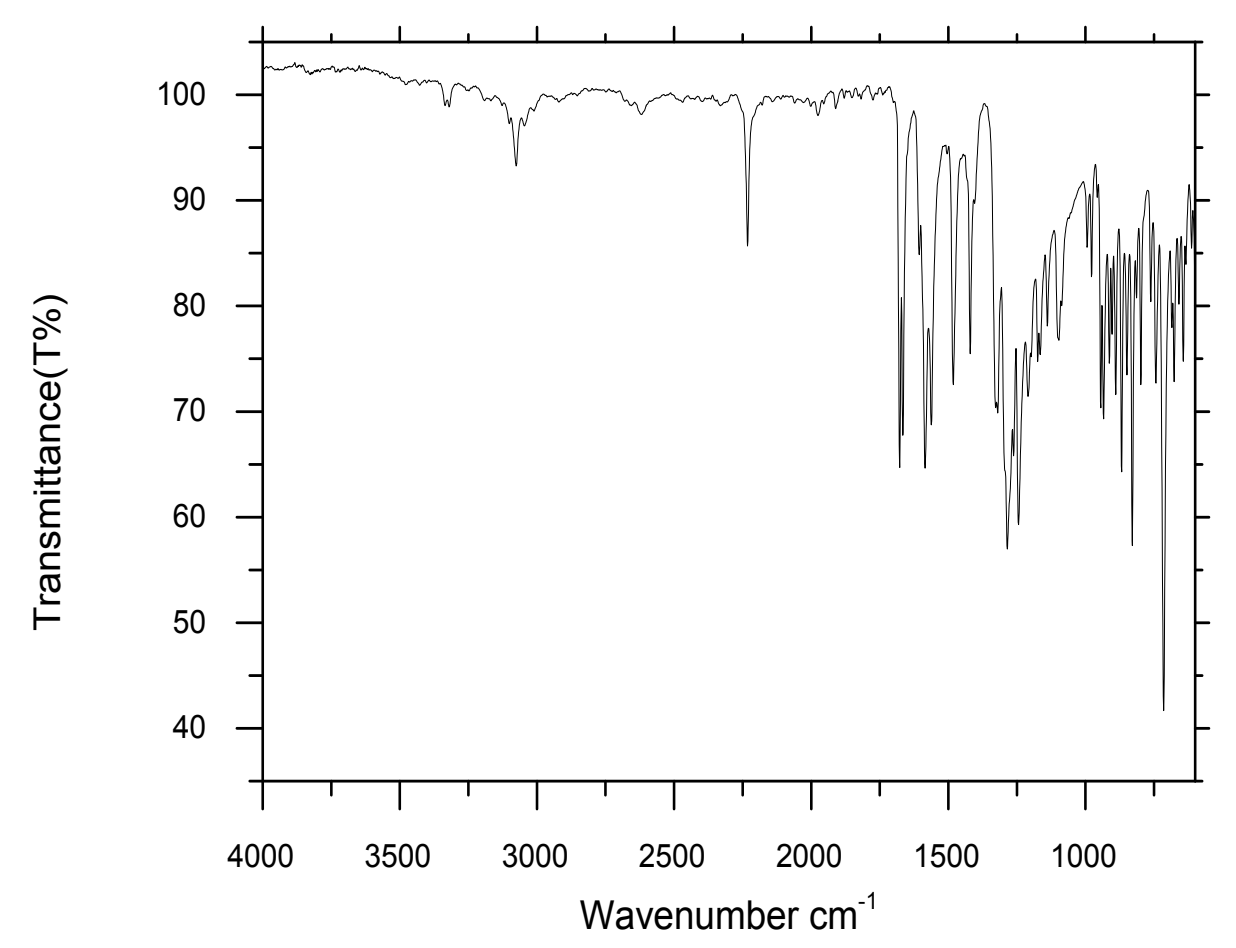

Figure S3. IR spectrum of $\mathbf{3}$ 


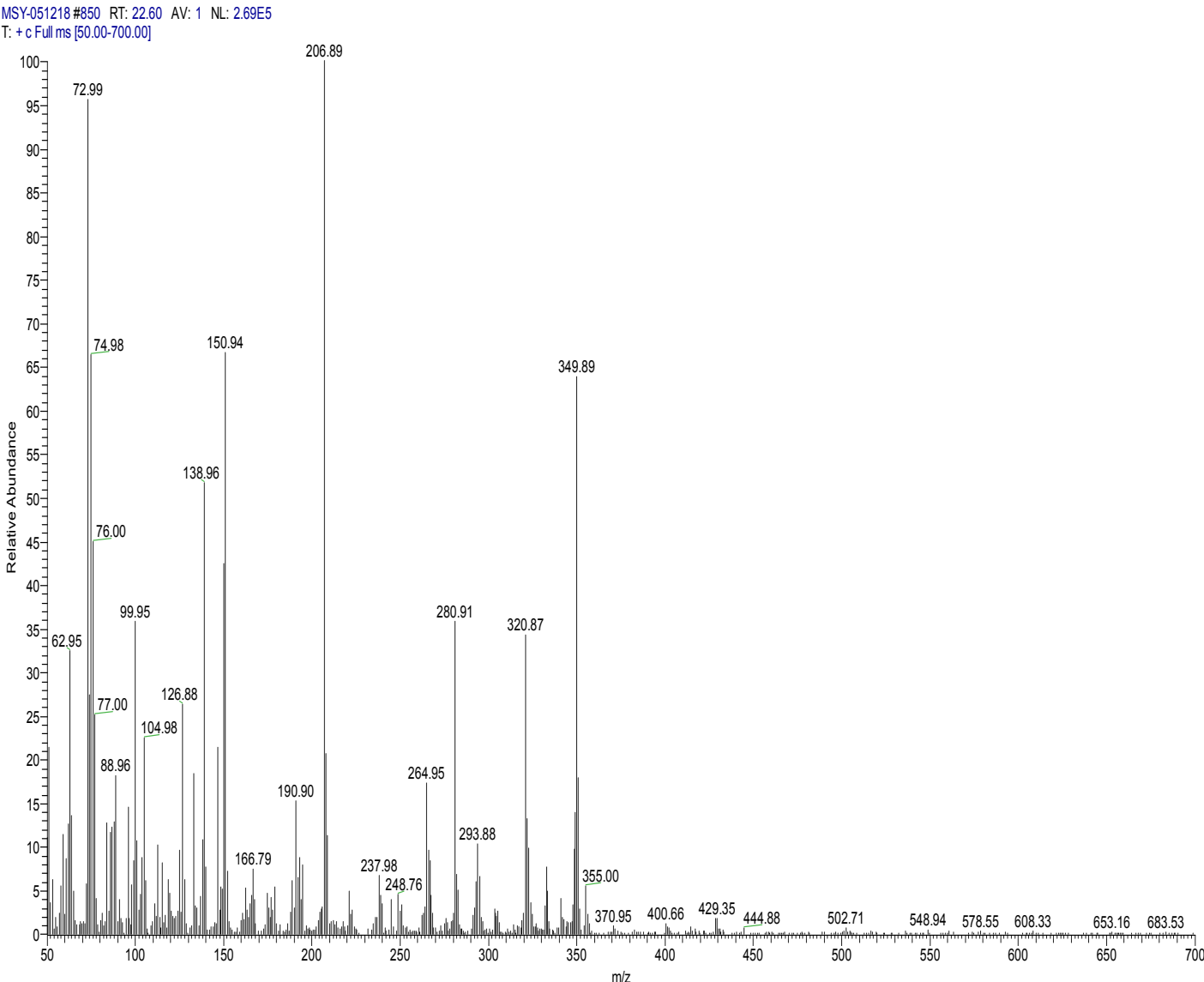

Figure S4. GC-Mass spectrum of $\mathbf{3}$ 


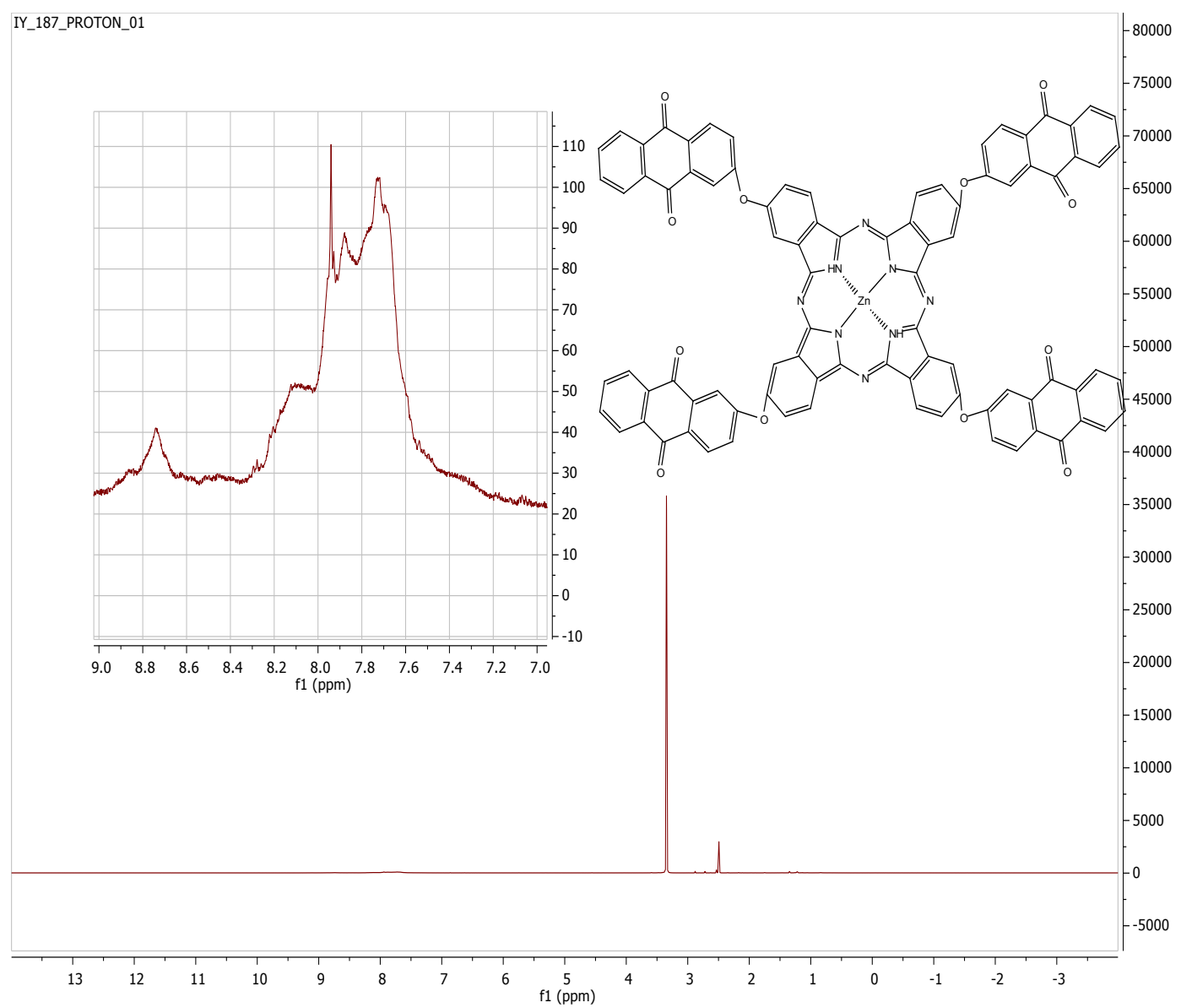

Figure S5. ${ }^{1} \mathrm{H}$ NMR spectrum of AQ-ZnPc 


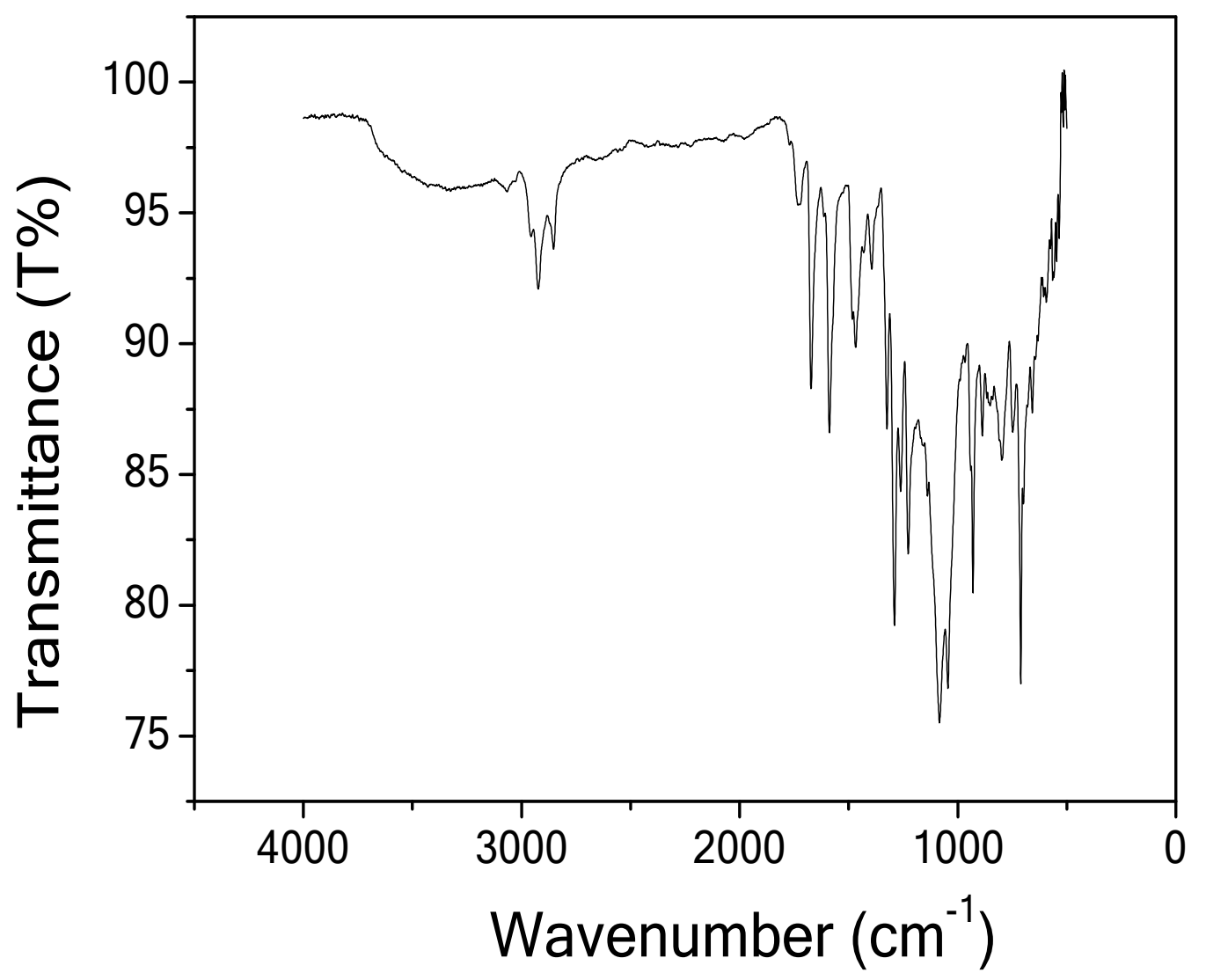

Figure S6. IR spectrum of AQ-ZnPc 


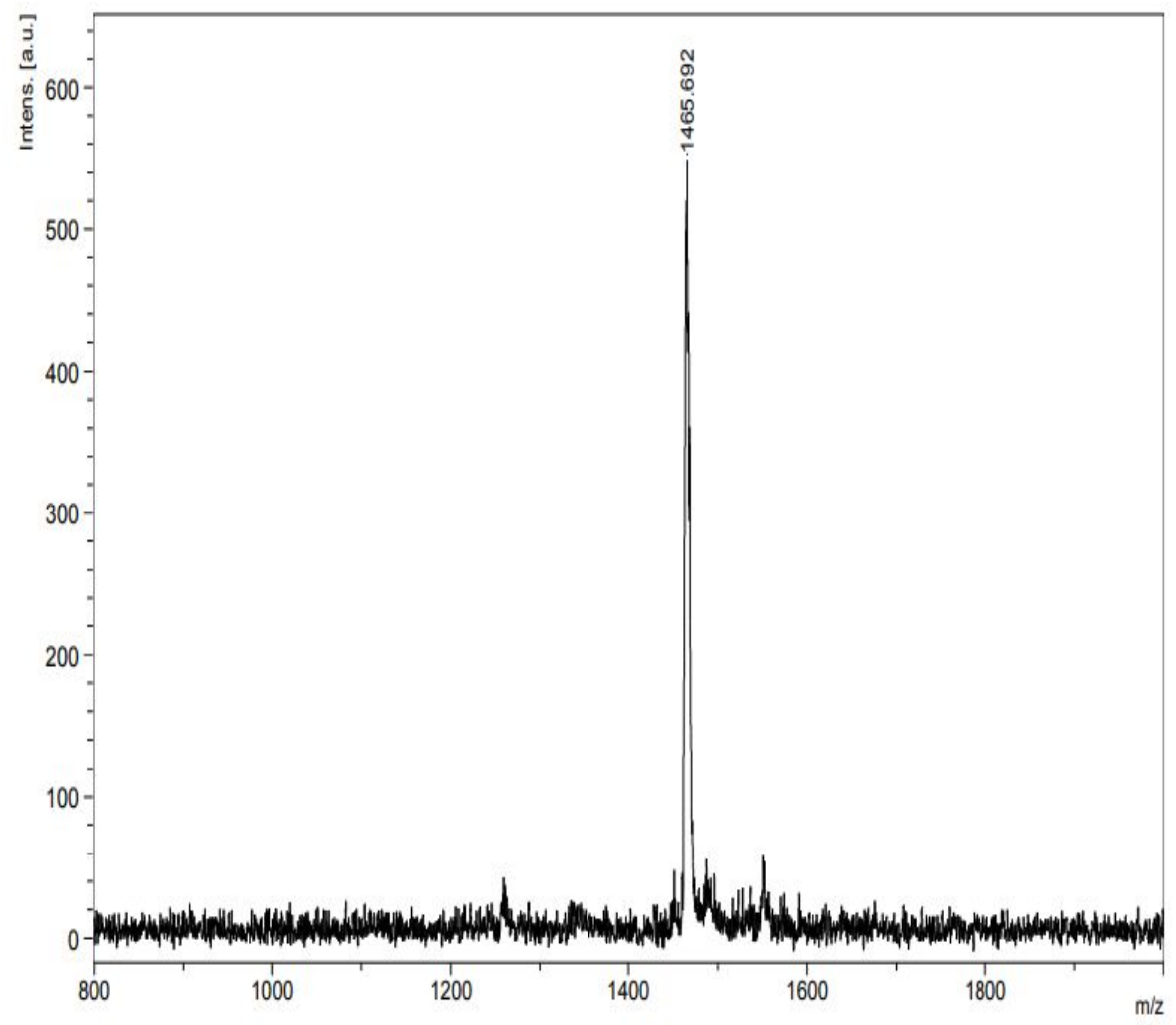

Figure S7. MALDI TOF mass spectrum of AQ-ZnPc.

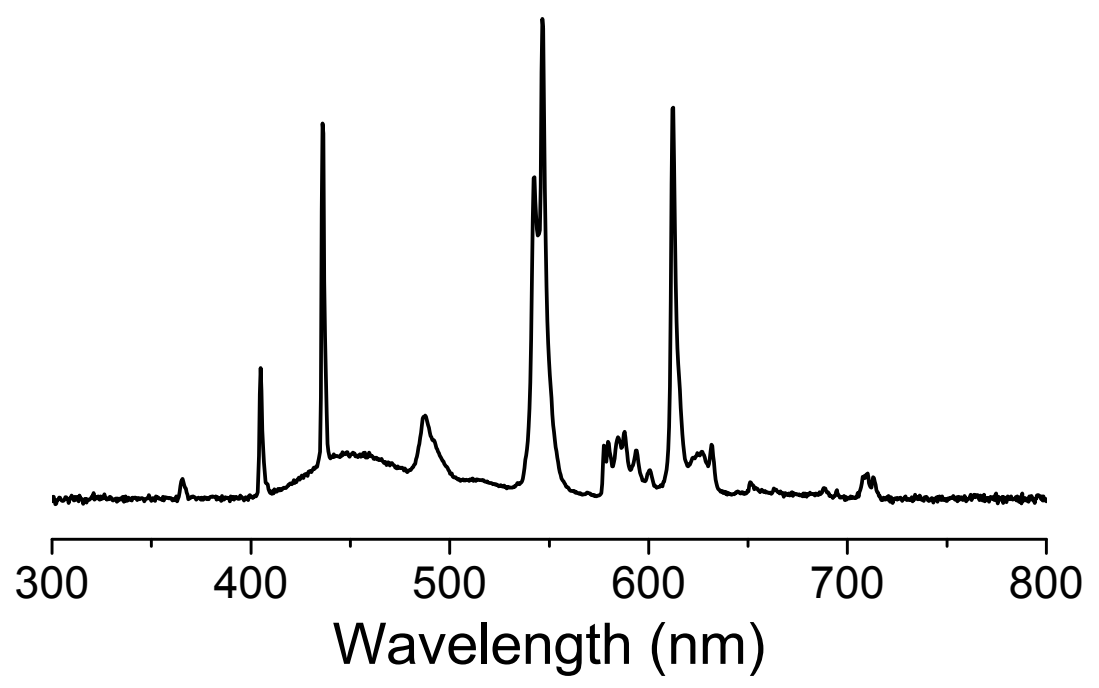

Figure S8. Emission spectrum of the lamps used during the different incubation times. 


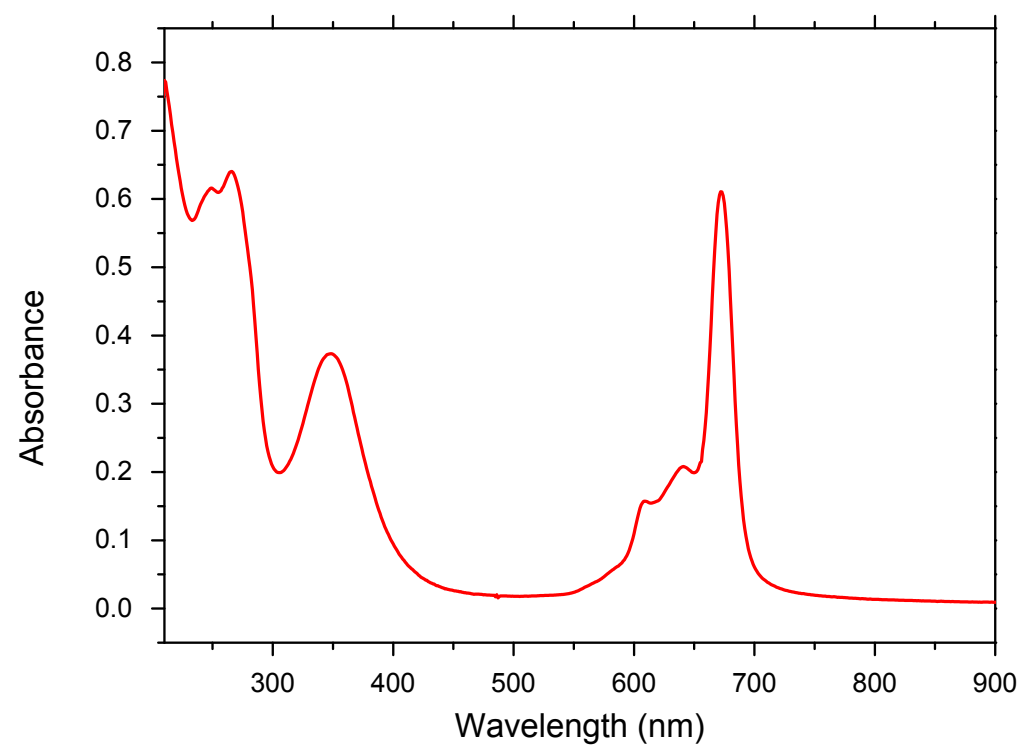

Figure S9. UV-vis spectrum of $4 \times 10^{-6} \mathrm{~mol} / \mathrm{L}$ AQ-ZnPc in THF

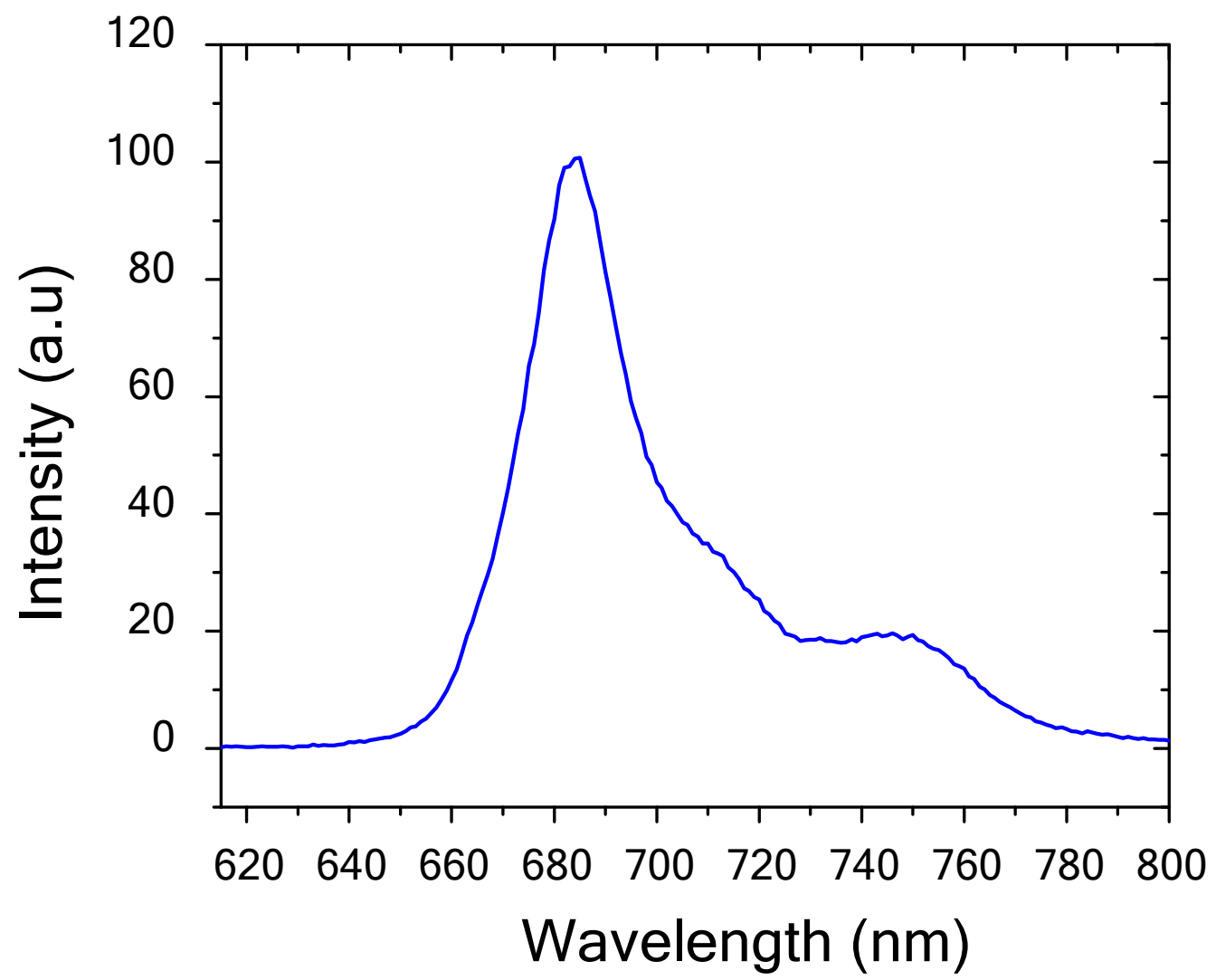

Figure S10. Fluorescence spectrum of $1 \times 10^{-5} \mathrm{~mol} / \mathrm{L}$ AQ-ZnPc in THF (slit width ex: $5 \mathrm{~nm}$ em: $5 \mathrm{~nm})$. 


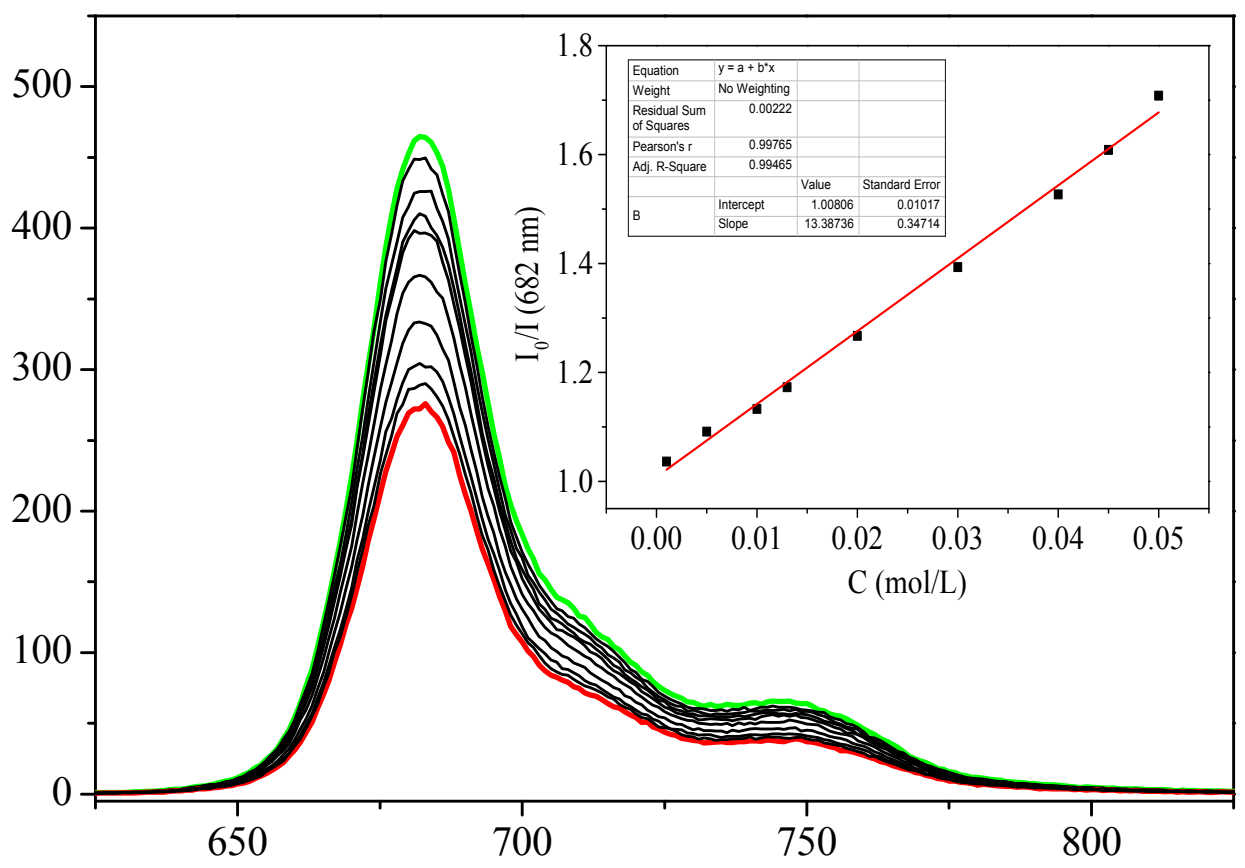

Figure S11. Quenching of the fluorescence of a THF solution of AQ-ZnPc by iodonium salt. 


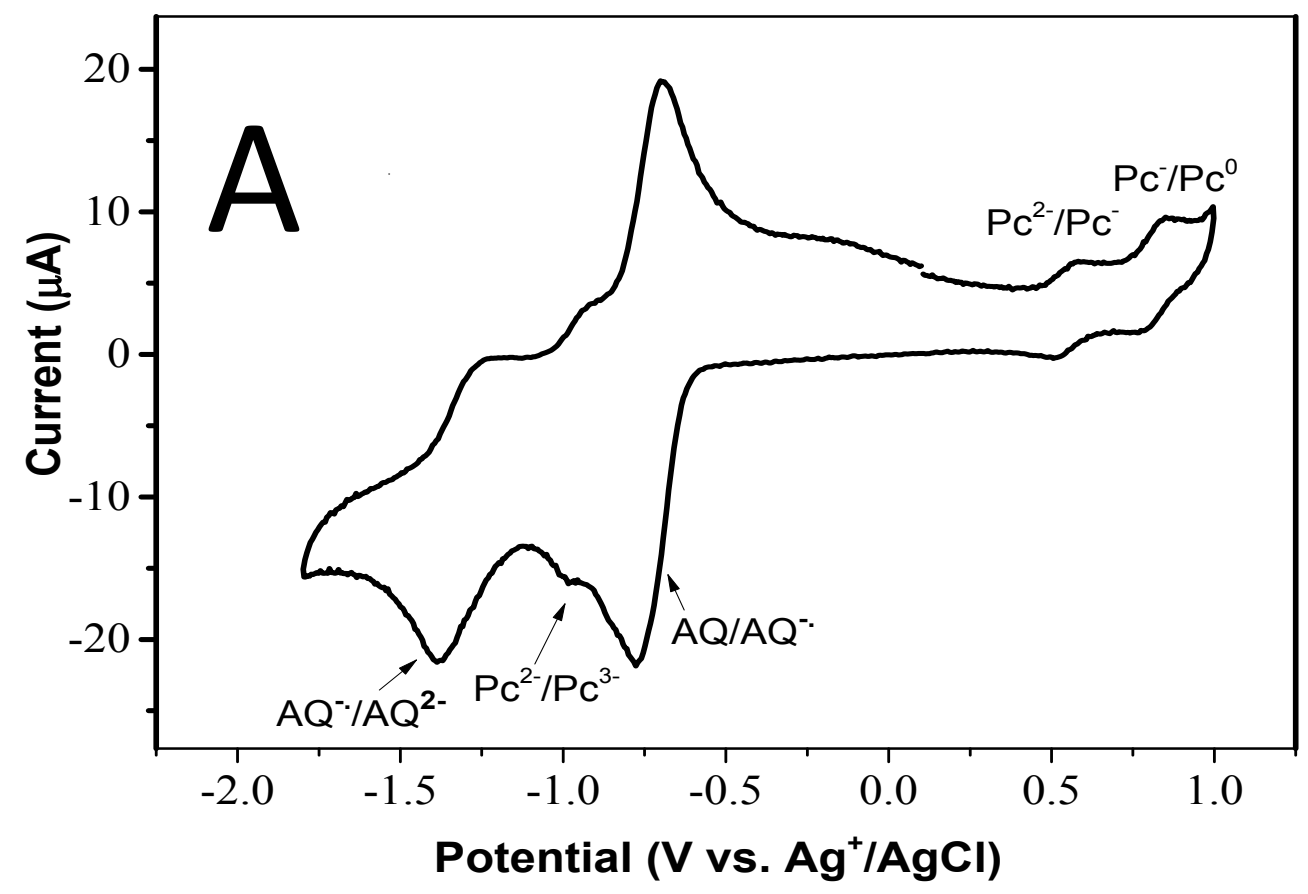




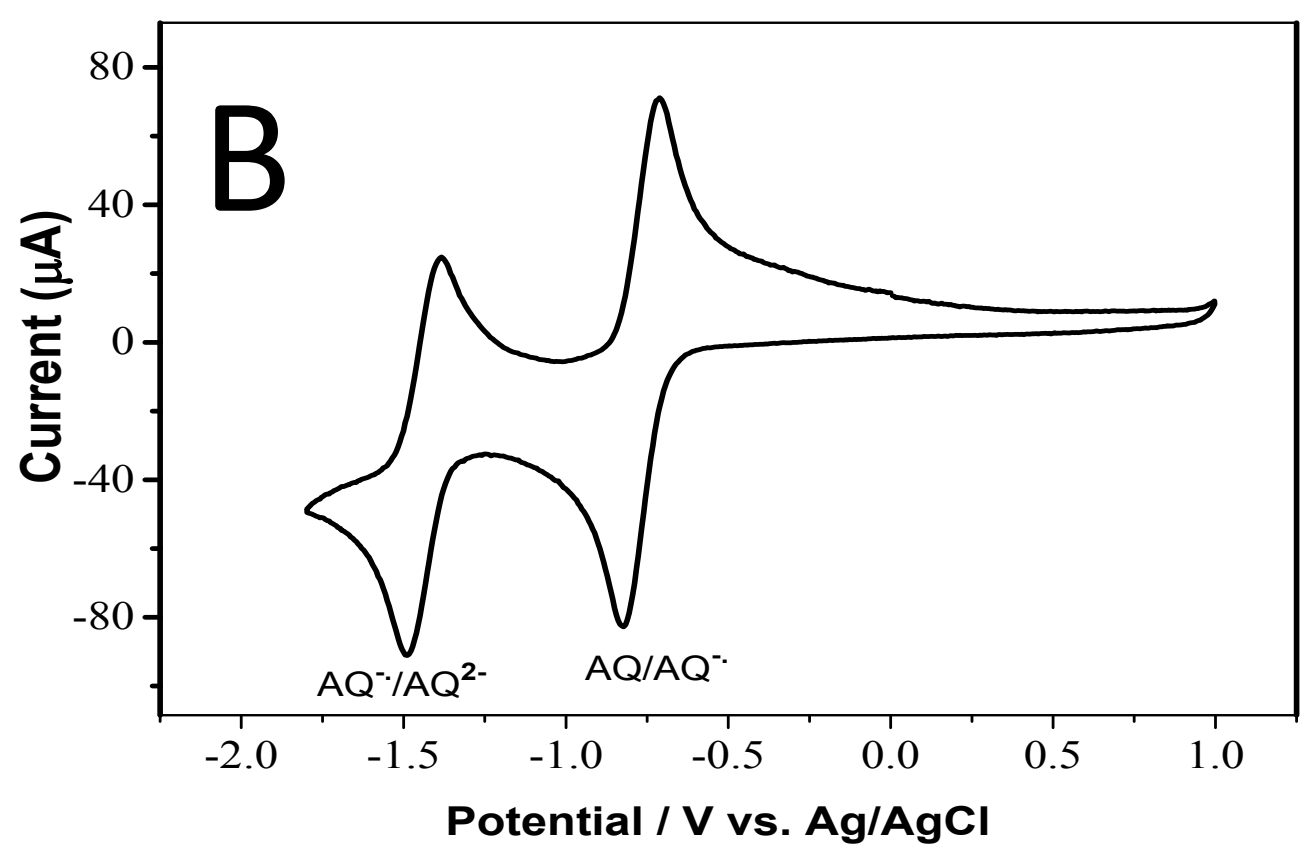

Figure S12. CV of A) AQ-Zn-Pc and B) anthraquinone in DMF solution containing $0.1 \mathrm{M}$ TBAP. Scan rate : 0.100 V.s ${ }^{-1}$

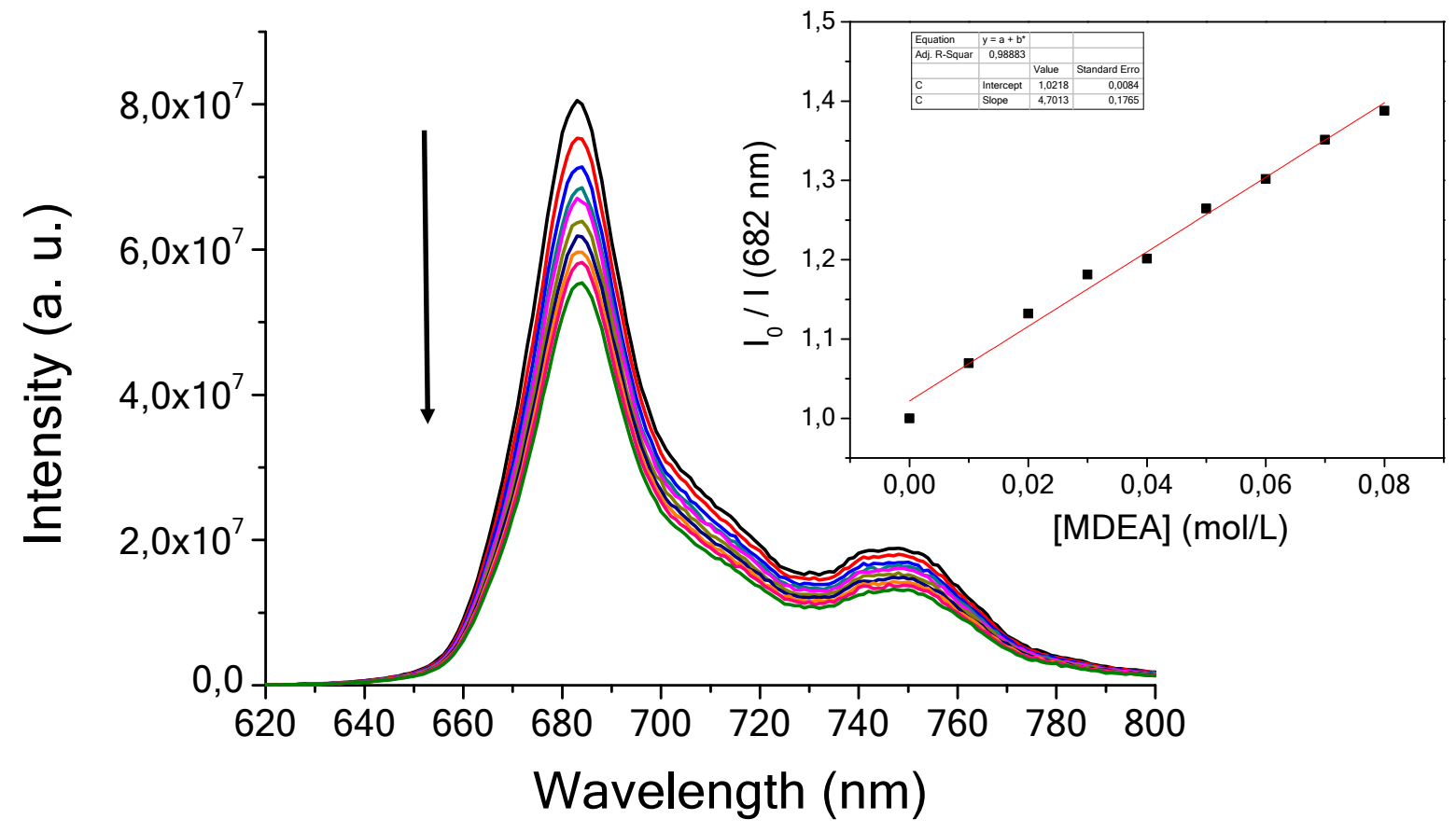

Figure S13. Quenching of the fluorescence of a THF solution of AQ-ZnPc by MDEA. 


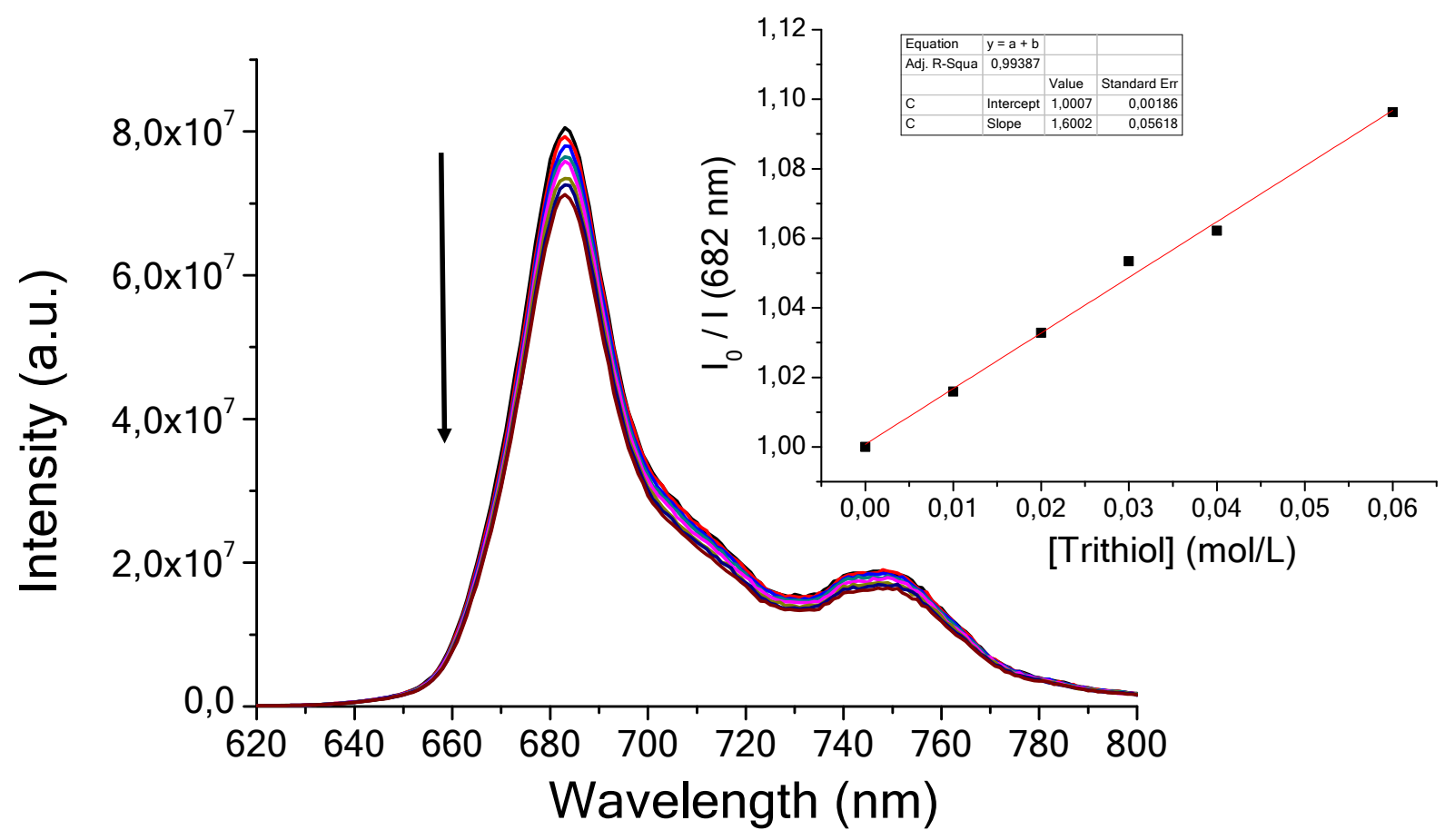

Figure S14. Quenching of the fluorescence of a THF solution of $\mathrm{AQ}-\mathrm{ZnPc}$ by trithiol.

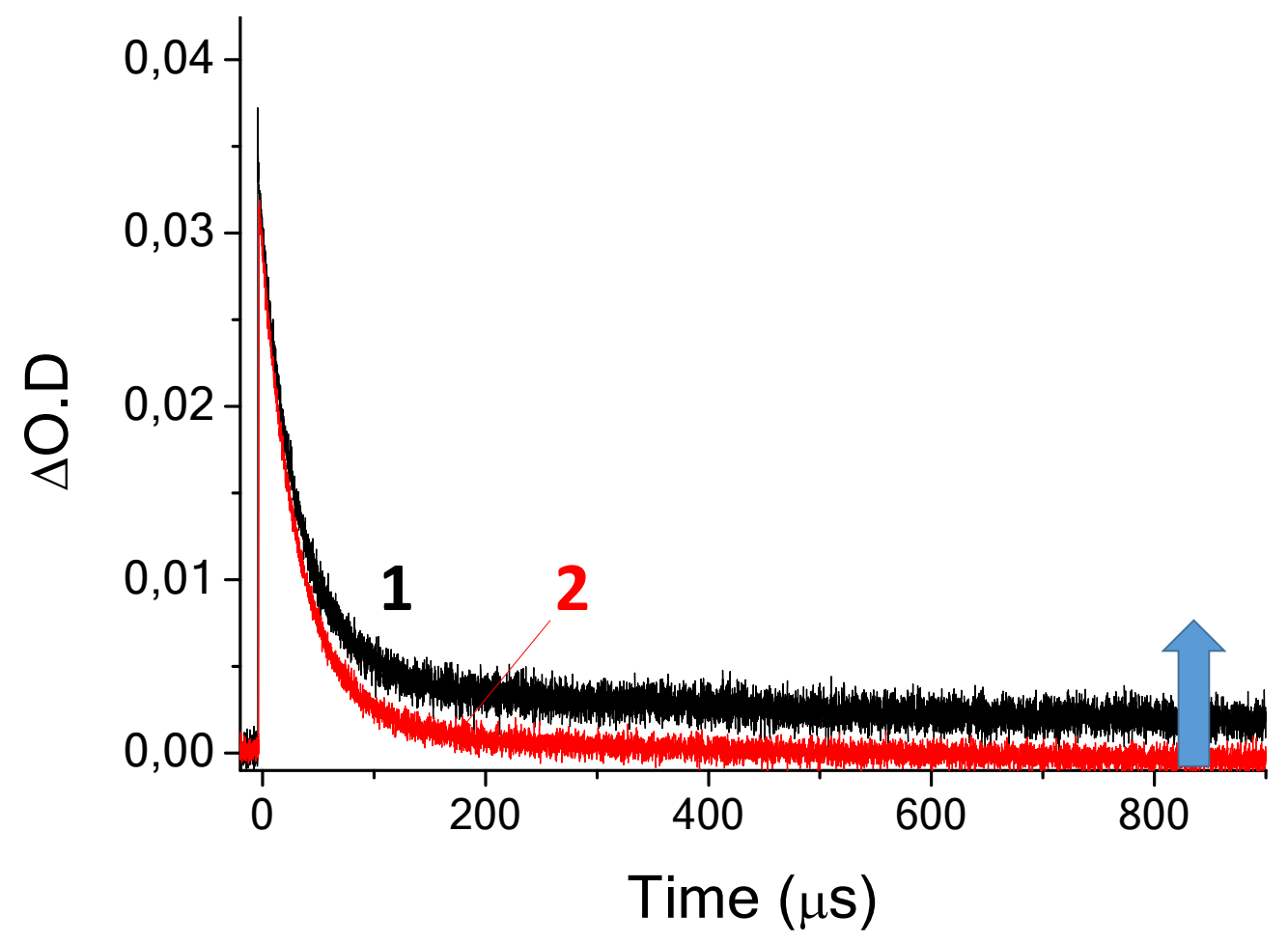


Figure S15. Transient absorption signal at $490 \mathrm{~nm}$ after $355 \mathrm{~nm}$ light irradiation of 1) AQZnPc/Iod and 2) AQ-ZnPc alone in DMSO.
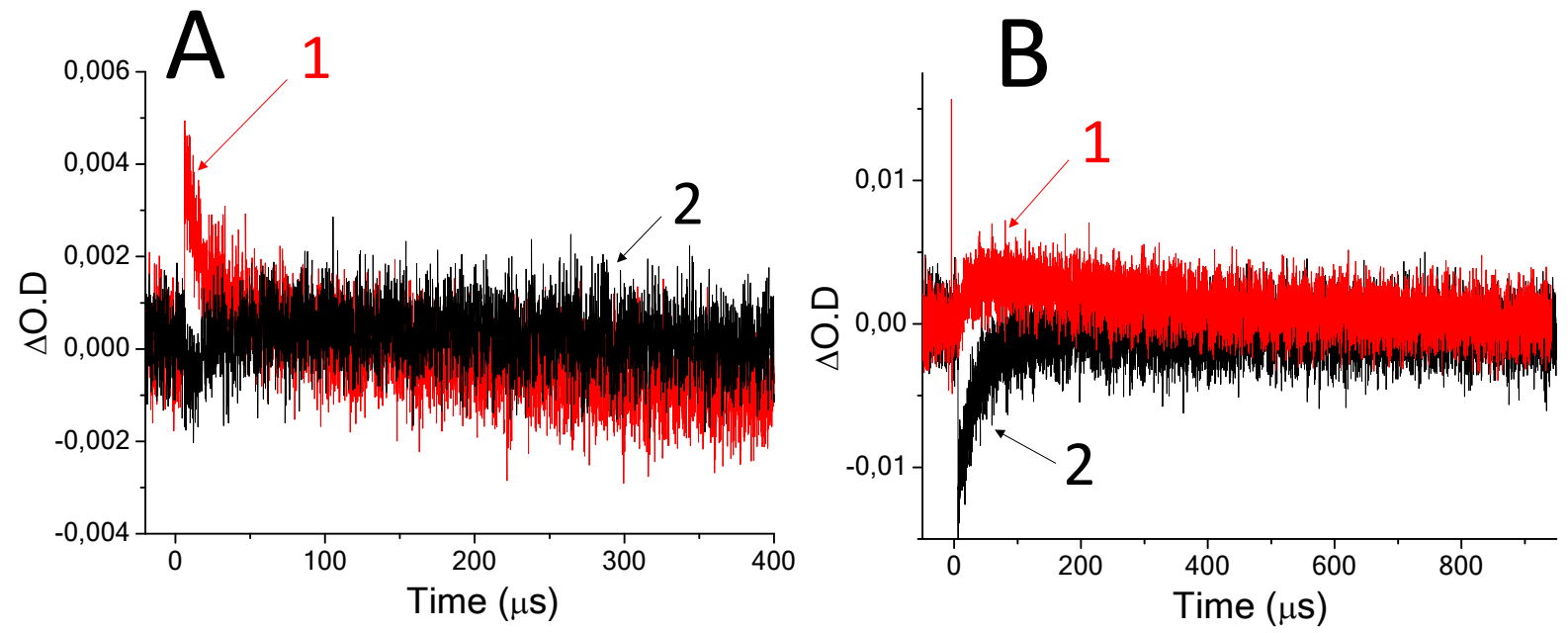

Figure S16. Transient absorption signal of AQ-ZnPc/Iod (line 1) and AQ-ZnPc alone (line 2) photoinitiating systems at A) $580 \mathrm{~nm}$ and B) $380 \mathrm{~nm}$.
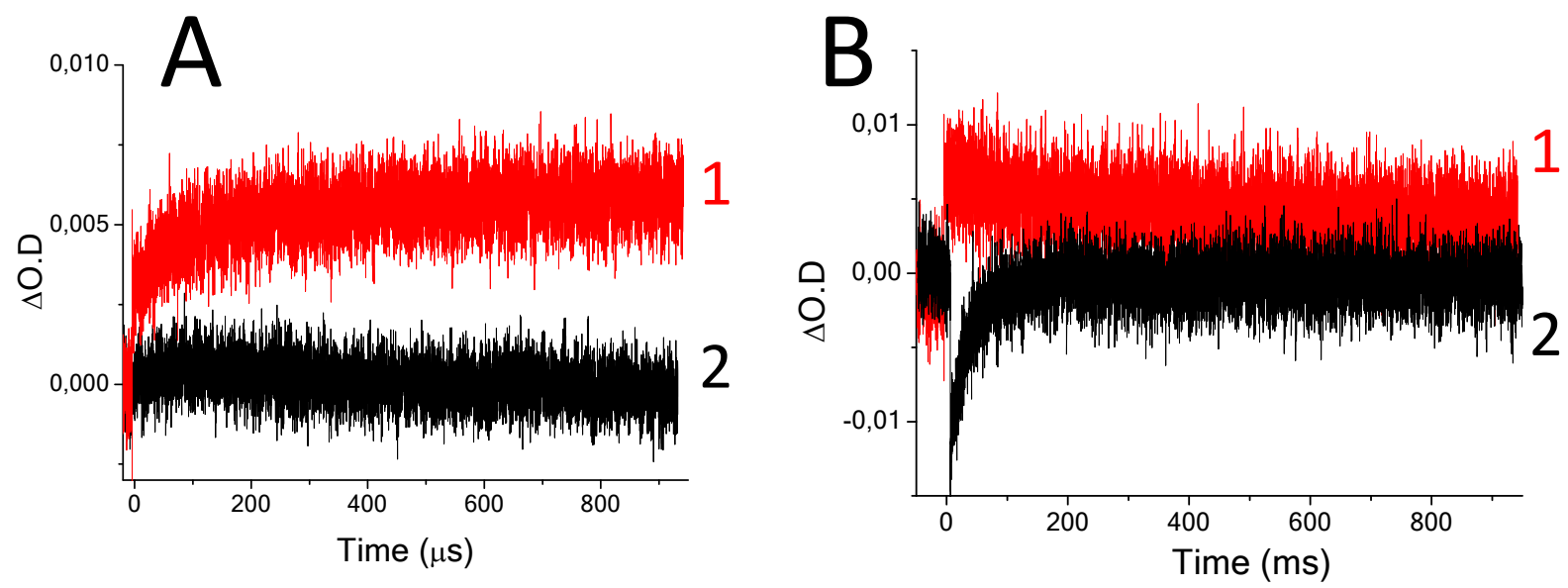

Figure S17. Transient absorption signal of AQ-ZnPc/MDEA (line 1) and AQ-ZnPc alone (line

2) photoinitiating systems at A) $580 \mathrm{~nm}$ and B) $380 \mathrm{~nm}$. 

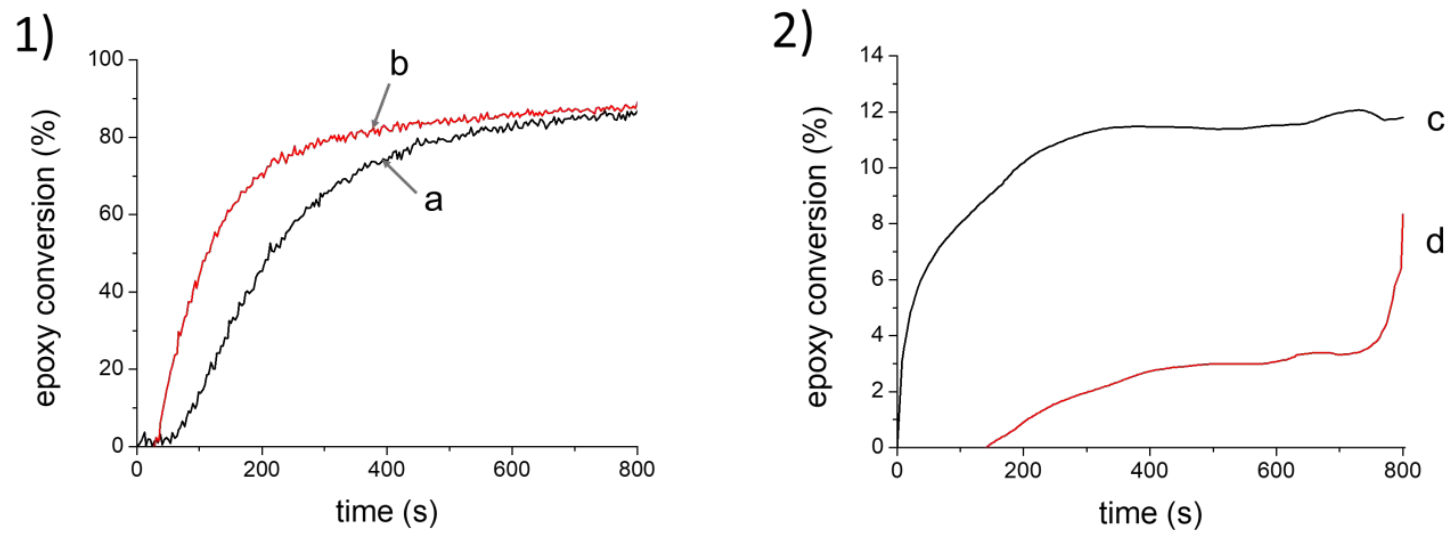

Figure S18. Kinetic profiles of the cationic photopolymerization of EPOX in the presence of

1) $\mathrm{HAQ} /$ Iod and 2) CQ/Iod under air upon a) LED $385 \mathrm{~nm}$, b) $405 \mathrm{~nm}$, c) $455 \mathrm{~nm}$ and d) 470 nm. Photoinitiator/ Iod $(0.25 / 5 \mathrm{w} \%)$.
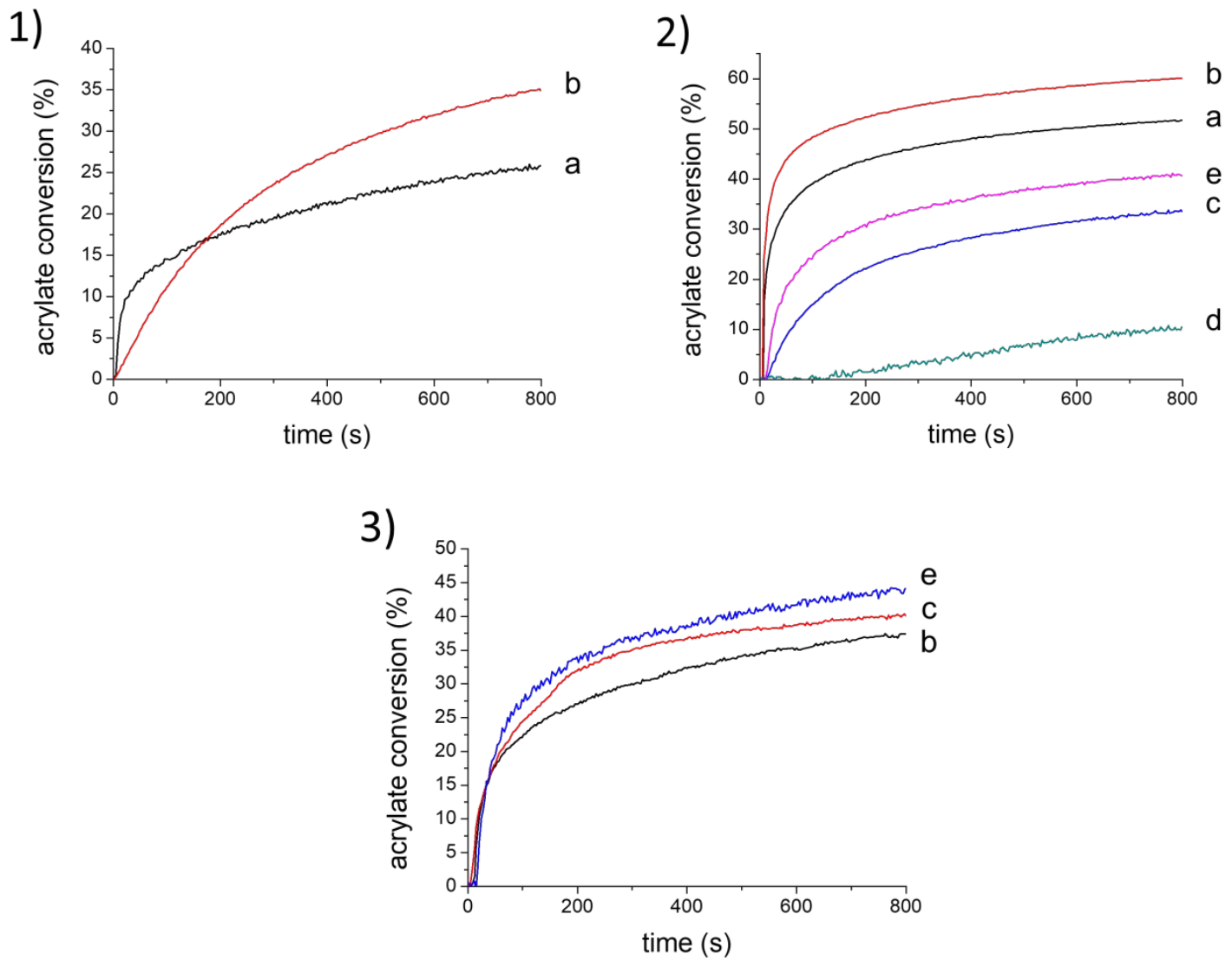

Figure S19. Kinetic profiles of the free-radical photopolymerization of TMPTA under laminated conditions in the presence of 1) $\mathrm{ZnPc} / \mathrm{TT}$, 2) $\mathrm{HAQ} / \mathrm{TT}$ and 3) $\mathrm{CQ} / \mathrm{TT}$ upon LED 
irradiation at a) $385 \mathrm{~nm}$, b) $405 \mathrm{~nm}$, c) $455 \mathrm{~nm}$, d) $470 \mathrm{~nm}$ and e) Xe lamp. Photoinitiator/ TT $(0.25 / 5 \mathrm{w} \%)$.

1)

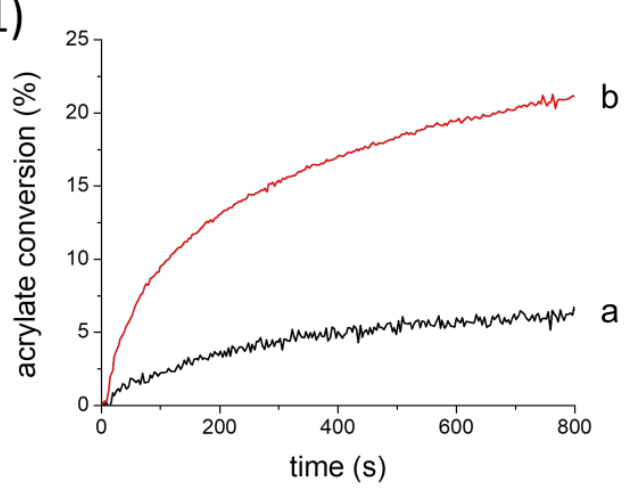

2)

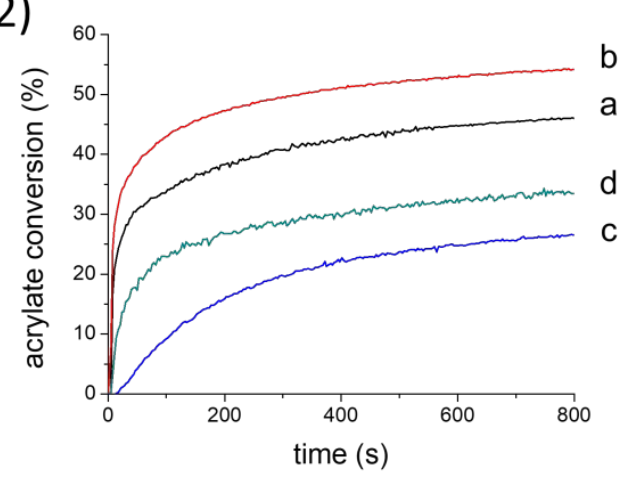

3)

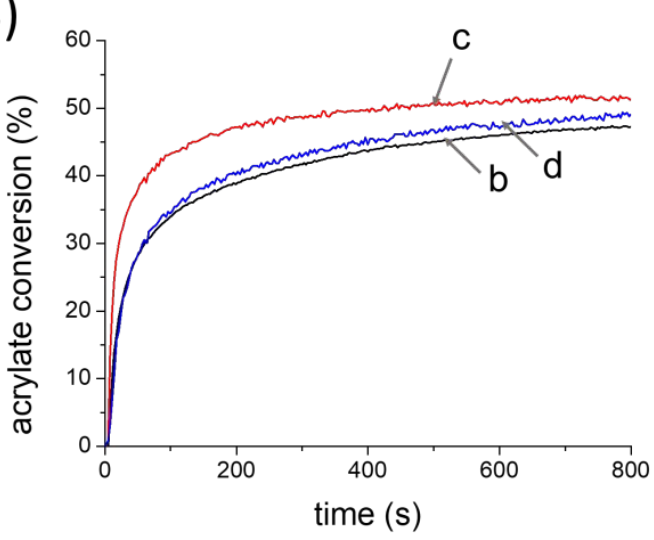

Figure S20. Kinetic profiles of the free-radical photopolymerization of TMPTA under laminated conditions in the presence of 1) ZnPc/MDEA, 2) HAQ/MDEA and 3) CQ/MDEA upon LED irradiation at a) $385 \mathrm{~nm}$, b) $405 \mathrm{~nm}$, c) $455 \mathrm{~nm}$, and d) Xe lamp. Photoinitiator/ TT $(0.25 / 5 \mathrm{w} \%)$. 
1)

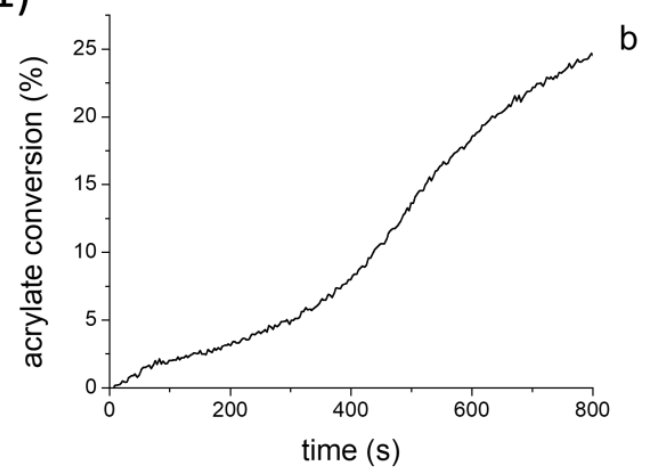

2)

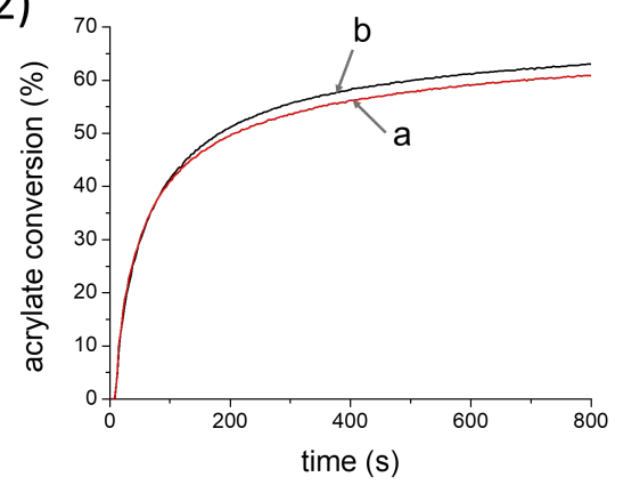

3)

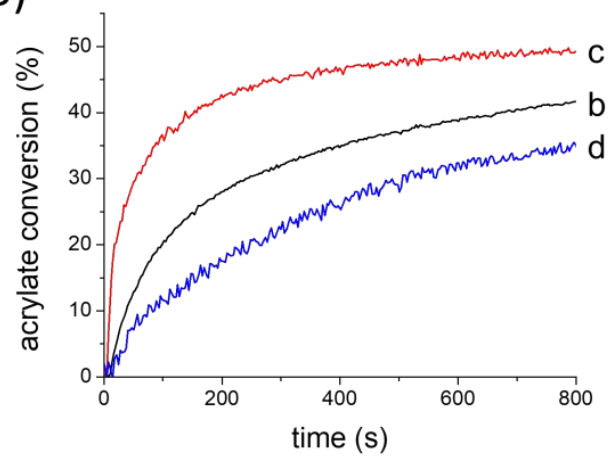

Figure S21. Kinetic profiles of the free-radical photopolymerization of TMPTA under laminated conditions in the presence of 1) $\mathrm{ZnPc} / \mathrm{Iod}$, 2) $\mathrm{HAQ} / \mathrm{Iod}$ and 3) $\mathrm{CQ} / \mathrm{Iod}$ upon LED irradiation at a) $385 \mathrm{~nm}$ and b) $405 \mathrm{~nm}$, c) $455 \mathrm{~nm}$ and d) Xe lamp. Photoinitiator/ Iod (0.25/5 w\%). 


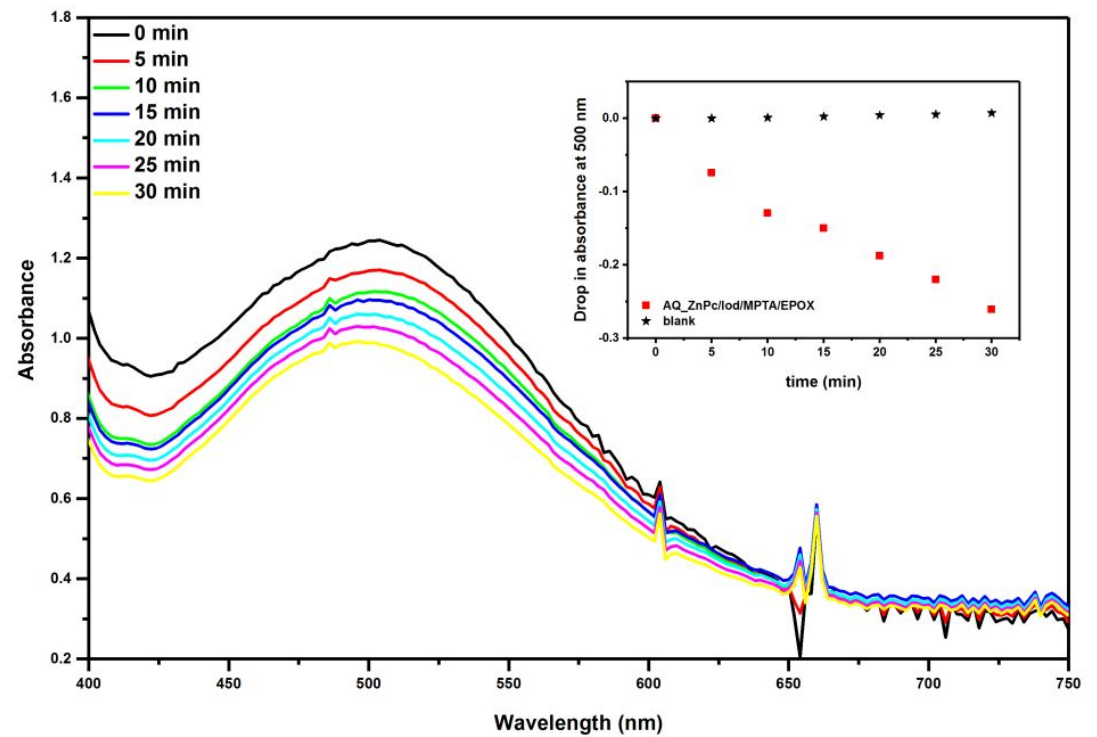

Figure S22. UV-Vis spectra of 2,3,4,5-tetraphenylcyclopentadienone (TPCPD) recorded during the illumination of $\mathbf{A Q - Z n P c / I o d / T M P T A / E P O X ~ c o a t i n g ~ b y ~ t h e ~ x e n o n ~ l a m p . ~ I n s e t : ~}$ drop in the absorbance at $500 \mathrm{~nm}$ during illumination of bare glass (blank) and AQZnPc/Iod/TMPTA/EPOX coating. 